\title{
A Práxis do Agente Comunitário de Saúde no Contexto do Programa Saúde da Família: reflexões estratégicas'
}

\section{The Community Health Agent's Praxis in the Context of the Family Health Program: strategic reflections}

\author{
Karine de Oliveira Gomes \\ Mestre em Ciência da Nutrição; Professora Auxiliar do Instituto \\ Multidisciplinar em Saúde, Campus Anísio Teixeira, Universidade \\ Federal da Bahia. \\ Endereço: Avenida Olívia Flores, n8 3000, Bairro Candeias, CEP \\ 45055-090, Vitória da Conquista, BA, Brasil. \\ E-mail: kogomesळyahoo.com.br

\section{Rosângela Minardi Mitre Cotta} \\ Doutora em Saúde Pública; Professora Adjunta do Departamento \\ de Nutrição e Saúde, Universidade Federal de Viçosa. \\ Endereço: Avenida P.H. Rolfs s/n, Campus Universitário, CEP 36571- \\ ooo, Viçosa, MG, Brasil. \\ E-mail: rmmitre®ufv.br
}

\section{Mariângela Leal Cherchiglia}

Doutora em Saúde Pública; Professora Adjunta do Departamento de Medicina Preventiva e Social, Universidade Federal de Minas Gerais.

Endereço: Avenida Alfredo Balena, 190, apt8 803, 88 andar, CEP 30130-100, Belo Horizonte, MG, Brasil.

E-mail: cherchmlळmedicina.ufmg.br

\section{Sandra Minardi Mitre}

Professora Assistente da Faculdade de Ciências Médicas de Minas Gerais; Mestranda em Saúde Pública no Departamento de Medicina Preventiva - UFMG; Especialista em Ativação de Processos de Mudanças na Formação Superior de Profissionais de Saúde.

Endereço: Alameda Ezequiel Dias, 275, 38 andar, CEP 30130-110, Belo Horizonte, MG, Brasil.

E-mail: sanmitreळterra.com.br

\section{Rodrigo Siqueira Batista}

Doutor em Ciências; Professor Adjunto do Departamento de Nutrição e Saúde, Universidade Federal de Viçosa.

Endereço: Avenida P.H. Rolfs s/n, Campus Universitário, CEP 36571ooo, Viçosa, MG, Brasil.

E-mail: rsiqueirabatistaœterra.com.br

I Este artigo é parte da dissertação "Programa Saúde da Família - da assistência ao cuidado: avaliação da implementação da Atenção Primária à Saúde", de Karine de Oliveira Gomes, Programa de Pós-Graduação em Ciência da Nutrição do Departamento de Nutrição e Saúde da Universidade Federal de Viçosa-MG; orientada pela Profa. Dra. Rosângela Minardi Mitre Cotta.

\section{Resumo}

O Programa Saúde da Família (PSF) surgiu no cenário brasileiro como estratégia de superação do modelo assistencial centrado na doença e no cuidado médico individualizado. Nesse contexto, os agentes comunitários de saúde (ACS) têm sido considerados atores-chave na implantação de políticas voltadas para a reorientação do modelo de atenção à saúde. 0 objetivo deste estudo foi analisar as concepções e percepções sobre o SUS e o PSF que norteiam as ações dos ACS, refletindo sobre sua função e formação profissional. 0 trabalho fundamentou-se na pesquisa quali-quantitativa, foi realizado em Cajuri-MG e foram entrevistados todos os ACS ( $n=11)$ que trabalhavam no PSF. Os resultados demonstraram que a maioria dos ACS $(72,7 \%)$ residia na comunidade em que atuava, trabalhava há mais de cinco anos no PSF e acompanhava a quantidade de famílias recomendada. Entre as principais funções, destacaram-se visitas domiciliares, busca ativa e educação em saúde, que na maioria das vezes acontecia de forma individualizada e centrada no reforço da assistência médica e na prevenção de riscos específicos. Em relação à capacitação, 54,6\% dos ACS receberam orientação antes de iniciar o trabalho e 81,8\% participaram de cursos depois que já estavam trabalhando. Apenas $27,3 \%$ dos ACS souberam conceituar o SUS e $36,4 \%$ demonstraram entendimento adequado sobre PSF. Esses resultados demonstram a necessidade de maiores esforços para melhorar a capacitação do ACS, visando adequar seu nível de apreensão e conhecimento dos princípios do SUS e PSF, para que ele possa atuar segundo as diretrizes desse sistema e contribuir efetivamente para sua consolidação.

Palavras-chave: Agente Comunitário de Saúde; Sistema Único de Saúde; Programa Saúde da Família; Formação Profissional. 


\section{Abstract}

Programa Saúde da Família (PSF - Family Health Program) appeared in the Brazilian scenario as a strategy to overcome an assistance model that is centered on disease and on individualized medical care. In this context, the agentes comunitários de saúde (ACS community health agents) have been considered key actors in the implementation of policies related to the reorientation of the healthcare model. The objective of this study was to analyze the conceptions and perceptions on Sistema Único de Saúde (SUS - National Health System) and PSF that guide the actions of the ACS, and to reflect on their function and professional education. The work was based on quantitative and qualitative research. It was carried out in Cajuri (state of Minas Gerais) and all the ACS ( $\mathrm{n}=11$ ) who worked in the PSF were interviewed. The results demonstrated that most of the ACS (72.7\%) lived in the community where they acted, had been working in the PSF for more than five years and followed up the recommended amount of families. Their main functions were home visits, active search and health education, which most of the time happened in an individualized way and focused on the reinforcement of medical aid and prevention of specific risks. In relation to qualification, $54.6 \%$ of the ACS received orientation before beginning the work and $81.8 \%$ participated in courses after they were already working. Only $27.3 \%$ of the ACS knew the concept of SUS and 36.4\% showed appropriate understanding of PSF. These results demonstrate the need of larger efforts to improve the qualification of the ACS, aiming to enhance their understanding and knowledge of SUS and PSF principles. Thus, they will be able to act according to the guidelines of this system and to contribute effectively to its consolidation.

Keywords: Community Health Agent; National Health System; Family Health Program; Professional Education.

\section{Introdução}

"A melhor maneira de tornar o impossivel possível é realizar o possivel hoje."

Paulo Freire (2002, p. 72)

O Programa Saúde da Família (PSF) surgiu no cenário brasileiro como estratégia de reorientação do modelo assistencial, justificada pela necessidade de substituição do modelo historicamente centrado na doença e no cuidado médico individualizado por um novo modelo sintonizado com os princípios do Sistema Único de Saúde (SUS), tais como universalidade, equidade, hierarquização e integralidade da atenção (Brasil, 2001; Scherer e col., 2005; Bornstein e Stotz, 2008).

Além disso, o PSF coloca em foco o paradigma da produção social da saúde, com ênfase no cuidado, na atenção primária e na prática sanitária da vigilância à saúde (Santos e Westphal, 1999; Mendes, 2006; Noronha e col., 2009).

Baseado numa nova dinâmica de organização dos serviços e ações de saúde, o PSF tem como principais características: a adscrição da clientela, através da definição de território de abrangência da equipe; o enfoque sobre a família, a partir de seu ambiente físico e social como unidade de ação; a estruturação de equipe multiprofissional; a ação preventiva em saúde; a detecção de necessidades da população no lugar da ênfase na demanda espontânea e a atuação intersetorial visando à promoção da saúde (Brasil, 2004, 2005).

Nesse contexto, os agentes comunitários de saúde (ACS) têm sido considerados personagens-chave na implantação das políticas voltadas para a reorientação do modelo de atenção em saúde e, portanto, não constituem mero suporte para a execução de determinadas ações em saúde (Nunes e col., 2002; Silva e Dalmaso, 2002).

Hoje o Brasil conta com o trabalho de 230.244 ACS, presentes tanto em comunidades rurais e periferias urbanas quanto em municípios altamente urbanizados e industrializados, cobrindo 6o,4\% da população do país. Apesar de ser um número ainda distante do desejado, é expressiva a importância desse profissional para o aumento do acesso aos serviços básicos de saúde, uma vez que a cobertura das Equipes de Saúde da Família (ESF) alcançou apenas 49,5\% da população em 2008 (Brasil, 2009). 
Desde o início, a vida profissional do ACS foi cheia de conflitos e incertezas, uma vez que o Programa de Agentes Comunitários de Saúde (PACS) foi criado em 1991 e suas atribuições foram definidas somente em 1997, pela Portaria No 1.886 (Brasil, 1997), que aprovou as normas e diretrizes do PACS/PSF. Em seguida, o Decreto No. 3.189/1999 fixou as diretrizes para o exercício da atividade dos ACS (Brasil, 1999), mas a regulamentação da profissão só aconteceu em 2002, com a promulgação da Lei No 10.507 (Brasil, 2002).

Considerando que dentre as características mais marcantes do PSF destaca-se a inclusão do ACS na equipe de saúde, como um elo entre a população e os demais profissionais da equipe, e por meio da vigilância à saúde, é objetivo desse estudo analisar as concepções e percepções sobre o SUS e o PSF que norteiam as ações dos ACS, refletindo sobre sua função e formação profissional.

\section{Metodologia}

\section{Descrição espaço-temporal e população estudada}

A pesquisa foi realizada em novembro de 2008 , no município de Cajuri, localizado na Zona da Mata de Minas Gerais, Brasil. Segundo o Instituto Brasileiro de Geografia e Estatística, o município tinha uma população estimada, em 2007, de 4.015 habitantes, dos quais $54,6 \%$ residiam na zona urbana (IBGE, 2008).

Em relação aos serviços de saúde, Cajuri possuía gestão plena da atenção básica na assistência à saúde, contando com uma unidade básica de referência que oferecia vacinação, curativos, farmácia, laboratório de exames, consultas médicas e de emergência, serviço de observação entre outros. Nesse mesmo espaço funcionava o PSF, que foi implantado no município em 1997, com apenas uma equipe e, atualmente, é constituído por duas equipes (Cajuri, 2008).

Foram entrevistados todos os ACS ( $n=11)$ que trabalhavam nas duas equipes de PSF. Investigaram-se as práticas de trabalho e a formação dos ACS, além de suas concepções e apreensões sobre o SUS e o PSF.

\section{Desenho do estudo}

O presente trabalho fundamentou-se na pesquisa quali-quantitativa. Essa dinâmica de investigação que integra a combinação e o cruzamento de múltiplos pontos de vista, assim como o emprego de uma variedade de técnicas de coleta de dados é conhecida como Triangulação de Métodos (Minayo, 2005), uma abordagem complementar e dialética que permite o diálogo entre questões objetivas e subjetivas (Minayo, 2007; Souza e col., 2005).

Os dados foram coletados por meio de entrevistas semiestruturadas, realizadas no próprio local de trabalho dos profissionais. Após livre consentimento dos participantes, as entrevistas foram gravadas e transcritas, respeitando a grafia e a sintaxe utilizadas pelos participantes do estudo na apresentação das falas. Com o intuito de preservar a identidade, os ACS receberam um número e suas falas foram caracterizadas pelo respectivo número ao final do depoimento.

Os dados quantitativos foram analisados por meio das distribuições de frequência da população estudada segundo as variáveis selecionadas. Com relação aos dados qualitativos, após leitura global e exaustiva das respostas dos entrevistados, foi realizada a análise de conteúdo, cumprindo três etapas: (1) Pré-análise, (2) Exploração do material e (3) Tratamento dos resultados, inferência e interpretação (Minayo, 2007; Bardin, 2008).

O trabalho foi aprovado pelo Comitê de Ética em Pesquisa com Seres Humanos da Universidade Federal de Viçosa - protocolo n ${ }^{0}$ 070/2008 -, em consonância com o disposto na Resolução 196/96 do Conselho Nacional de Saúde.

\section{Resultados e Discussão}

\section{Caracterização dos entrevistados}

Todos os ACS de Cajuri eram do sexo feminino e recebiam 1 salário-mínimo, equivalente a R\$ 415,0o na época do estudo. Quanto ao perfil dos ACS de Cajuri, a maioria era católica (90,9\%) e tinha entre 30 e 40 anos (63,6\%) (Tabela 1). Todos também haviam concluído o Ensino Fundamental, atendendo ao grau de escolaridade recomendado pelo Ministério da Saúde, conforme a Lei №. 10.507 (Brasil, 2002).

Em relação ao trabalho, a maioria dos ACS (72,7\%) residia na comunidade em que atuava e estava há mais de cinco anos trabalhando no PSF. Verificou-se que 27,3\% dos ACS acompanhavam um número de famílias acima do recomendado pelo Ministério da Saúde, de acordo com a Portaria № 1.886 (Brasil, 1997). 
Tabela I - Distribuição do $n^{\circ} e$ \% dos ACS do Programa Saúde da Família segundo variáveis demográficas - Cajuri-MG, Brasil, 2008

\begin{tabular}{|c|c|c|}
\hline Variáveis & $n$ & $\%$ \\
\hline \multicolumn{3}{|l|}{ Faixa etária (anos) } \\
\hline $20 \vdash 30$ & 3 & 27,3 \\
\hline $30 \vdash 40$ & 7 & 63,6 \\
\hline $40 \vdash 50$ & 1 & 9,1 \\
\hline \multicolumn{3}{|l|}{ Estado civil } \\
\hline Solteira & 5 & 45,4 \\
\hline União estável & 5 & 45,4 \\
\hline Viúva & 1 & 9.2 \\
\hline \multicolumn{3}{|l|}{ Escolaridade } \\
\hline Fundamental completo & 2 & 18,1 \\
\hline Médio incompleto & 3 & 27,3 \\
\hline Médio completo & 3 & 27,3 \\
\hline Superior incompleto & 3 & 27,3 \\
\hline \multicolumn{3}{|l|}{ Religião } \\
\hline Católica & 10 & 90,9 \\
\hline Evangélica & I & 9,1 \\
\hline \multicolumn{3}{|l|}{ Área de trabalho } \\
\hline Rural & 5 & 45,4 \\
\hline Urbana & 2 & 18,2 \\
\hline Rural e urbana & 4 & 36,4 \\
\hline \multicolumn{3}{|l|}{ Reside onde trabalha } \\
\hline $\operatorname{sim}$ & 8 & 72,7 \\
\hline Não & 3 & 27,3 \\
\hline \multicolumn{3}{|c|}{ Tempo de trabalho no PSF (anos) } \\
\hline$<1$ & 1 & 9,1 \\
\hline $1-5$ & 2 & 18,2 \\
\hline$>5$ & 8 & 72,7 \\
\hline \multicolumn{3}{|c|}{ Número de famílias acompanhadas } \\
\hline$\leq 150$ & 8 & 72,7 \\
\hline$\geq 151$ & 3 & 27,3 \\
\hline
\end{tabular}

\section{Atribuições do Agente Comunitário de Saúde: conflitos entre teoria e prática}

Segundo a Política Nacional de Atenção Básica (Brasil, 2007), são atribuições dos ACS: promover a integração da equipe de saúde com a população; trabalhar com adscrição das famílias em base geográfica definida; desenvolver ações educativas com as famílias; realizar e atualizar os cadastros; orientar as famílias quanto à utilização dos serviços de saúde disponíveis; desenvolver atividades de promoção da saúde, prevenção das doenças e agravos, e de vigilância à saúde, mantendo a equipe informada sobre as famílias em situação de risco; acompanhar, por meio de visita domiciliar, todas as famílias e indivíduos sob sua responsabilidade e ajudar na prevenção/controle da malária e da dengue.

Diante disso, o ACS pode ser visto como um trabalhador sui generis, uma vez que suas funções transcendem o campo da saúde, exigindo-lhe atenção a múltiplos aspectos das condições de vida da população (Nogueira e col., 200o).

Vários estudos têm procurado identificar as funções, ações e concepções sobre o cotidiano do trabalho do ACS, e os resultados demonstram que eles têm encontrado muitas dificuldades para cumprir com suas atribuições, tanto pelo amplo leque de exigências quanto pelas limitadas condições socioeconômicas das famílias que acompanham (Nunes e col., 2002; Silva e Dalmaso, 2002; Levy e col., 2004; Ferraz e Aerts, 2005; Zanchetta e col., 2005; Buchabqui e col., 2006; Duarte e col., 2007; Bornstein e Stotz, 2008).

No município de Cajuri, todas as ações relatadas pelos ACS estavam em conformidade com o previsto pela Política Nacional de Atenção Básica, sendo a visita domiciliar e a orientação as atividades mais citadas. Aqui merece destaque a busca ativa realizada através das visitas domiciliares, conforme pode perceber-se nos depoimentos que seguem:

“... Aqui o PSF, ele busca! [...] Porque a gente tá treinado pra isso, né? Os ACS é treinado pra fazer a busca ativa na casa, né?" ACS 1.

"Ajudá mais os pessoal da comunidade, mas porém, não ficá parado no posto, nóis temos que levá a notícia, procurá sabê onde que tá a notícia pra podê nóis passá pro pessoal que tá lá dentro, né? Que através de nós é que eles sabe das informação tudo." ACS 9. 
"A gente tenta busca as pessoas pra melhorá. [...] Tem pessoas que às vezes a gente insiste, procura eles, mas eles inda tem vez num dá atenção pra gente. Mas a gente num desiste, volta lá de novo, insiste com a pessoa até a gente conseguí e a gente consegue, né?!" ACS 10.

Embora a portaria $n^{\circ} 648$ (Brasil, 2007) não estabeleça um número mínimo de visitas domiciliares que o ACS deve realizar por dia, ela recomenda que todas as famílias sejam visitadas pelo menos uma vez ao mês. Em Cajuri, os ACS realizavam, em média, 13 visitas domiciliares por dia e $45,4 \%$ dos ACS conseguiam visitar todas as famílias no mês. Dentre aquelas que relataram não conseguir cumprir a recomendação, $27,3 \%$ afirmaram que isso acontecia eventualmente e em função de algum imprevisto.

"Tem vez que cê tá planejano ínuma casa hoje. [...] Aí chega um papel dum exame que é lá no outro lado! Então aquela casa tem vez que fica sem í.” ACS 8.

"Às vezes a gente vai numa casa na zona rural e não tem ninguém em casa, aí a gente programa pá outro dia, de repente não dá pra voltá, aí essa casa às vezes fica... Mas no outro mês a gente já procura ílá visitá. [...] Primeiramente lá nessa casa." ACS 10.

O acompanhamento dos grupos de risco, como crianças, gestantes, hipertensos, diabéticos, pacientes da saúde mental e acamados, também foi bastante citado pelos ACS, com os quais eles trabalhavam principalmente a educação em saúde. Resultados semelhantes foram encontrados por Levy e colaboradores (2004), em Bauru, e por Ferraz e Aerts (2005), em Porto Alegre, onde os ACS também ressaltavam os cuidados com a higiene e prevenção da dengue, a importância do cumprimento do calendário vacinal das crianças e do acompanhamento pré-natal das gestantes, incentivo à amamentação e uso correto das medicações.

“É pra tá orientando as famílias (pausa) sobre o cuidado que devem ter com... A higiene bucal, é... Também com alimentação e com a limpeza do quintal pra evitá, pra evitá a ação do mosquito da dengue." ACS 7.

"É orientando as mães como começa o primeiro dia a amamentação com o bebê, né?" ACS 9.

"Tem que olhá cartão de criança, né, tem que sabê se tá perto de tomá vacina. [...] Tem mais é as ges- tantes, né, elas e assim as pessoas que tem assim é, pressão muito alta, né?! [...] A gente acompanha mais, pede eles pá caminhá, né, pá tomá o remédio direitim, né?!" ACS 11.

Embora o enfoque preventivo seja tão enfatizado nas atividades dos ACS, observa-se que o trabalho de orientação acontece de forma individualizada, centrada no reforço da assistência médica e na prevenção de riscos específicos, deixando a impressão de que sua abordagem, na maioria das vezes, não considera a dinâmica familiar, mas o somatório dos indivíduos que coabitam o domicílio (Silva e Dalmaso, 2002; Duarte e col., 2007). Além disso, nos depoimentos dos ACS, em vários momentos as visitas domiciliares foram associadas à entrega de medicamentos e resultados de exames e ao agendamento de consultas:

"Às vezes é consultas que tem que agendar, remarcar consulta, tem casas que realiza vários tipos de exames, aía gente tem que ir lá pra avisar consulta, essas coisas assim." ACS 1.

"Temos a entrega de medicamento, que é, eles nem procuram o posto, entendeu, a gente leva nas casas! [...] O hiperdia né, que ele já passa pelo médico e a gente encarrega de entregá os medicamento pra eles." ACS 6.

Se, por um lado, essa função designada ao ACS amplia o acesso da população às ações e serviços de saúde (Silva e col., 2005), por outro pode prejudicar o acompanhamento das famílias quando se torna o objetivo maior da visita domiciliar.

Outro paradoxo relacionado à atuação do ACS é o alto grau de intervencionismo na vida das pessoas (Campos, 2007), percebido principalmente quando os critérios de avaliação da saúde ou do modo de vida das pessoas da comunidade são exclusivamente guiados pelas recomendações biomédicas, sem esforço de contextualização ou reflexão sobre sua realidade (Nunes e col., 2002; Silva e Dalmaso, 2002). Esse comportamento ilustra um dos problemas da visita domiciliar que, segundo Franco e Merhy (1999), pode significar uma excessiva intromissão na vida das pessoas, limitando sobremaneira seu grau de privacidade e liberdade.

"Então eu tenho que passá pra ver se eles tão tomando o medicamento. Aí eu já tenho até, eu já faço a caxinha separando com desenhos, né, os remédios que eles têm que tomá e nem coloco muito remédio, 
porque eu tenho que passa lá direto. Devo ir lá umas 20... 20 vezes ou mais! (risos) Tem analfabeto que é complicado, cê tem que sempre tá lá pra ver se num tá trocando remédio, né?!" ACS 2.

"É um paciente que às vezes eu tenho que tá olhano, vigiano porque às vezes come uma comida salgada, eu tenho que tá em cima ali pedino pá num, né, pá fazermais sem sal, tudo isso, né! Gordura, né?! Evitá as gordura! Tem uma casa que às vezes o quintal é sujo eu tenho que tá olhano, vê se limpô, né, a casa bem limpinha! Um paciente acamado que eu tenho que tá olhano se a cama tá limpinha, né, se o paciente tá bem cuidado." ACS 3.

Por outro lado, muitas vezes os ACS reproduzem comportamentos calcados em velhas concepções de favores e facilitação dos trâmites burocráticos (Cotta e col., 1998; Pedrosa e Teles, 2001), colocando em jogo na sua relação com a família e com a equipe não só os procedimentos necessários aos cuidados da saúde, mas também relações de barganha e poder para a geração de privilégios (Silva e Dalmaso, 2002; Nunes e col., 2002).

“... Às vezes, nós como as agentes, a gente faz, né, a nossa parte que é fazer as fichas pros pacientes. Eu entro na fila e faço a ficha, aí depois quando ele chega já ta com o número lá.” ACS 2.

"Ah, custô pra me atendê e tal... Ah, é porque cê num me procurou, porque quando cê me procura as coisas é mais rápida (risos)!” ACS 4.

"Quando a gente precisa de alguma coisa pra família da gente. [...] Um exame, né, ou mesmo consulta, marcá consulta, então a gente, é... Não que a gente seja favorito mais do que as outras pessoas, né, mas eu acho que a gente é atendido assim muito rápido! [...] Eu tenho uma irmã que mora lá em Volta Redonda, né, e ela vem aqui de dois em dois meses pá consultá com o médico aqui" ACS 11.

Atitudes como essas, em que os ACS favorecem o acesso a pessoas mais próximas ou afins, remetem ao velho jogo clientelista, típico do país nos anos que antecederam o SUS, que, ainda hoje, está presente em muitos municípios brasileiros, especialmente nos de pequeno porte (Cotta e col., 1998; Fleury, 2006).

Entretanto, essa prática não é dominante no município pesquisado, conforme ilustram os depoimentos que se seguem e que vai ao encontro de diferentes estudos, que apontam para o fato de que, de modo geral, o ACS é percebido como o elo entre a equipe de saúde e a comunidade, sendo o principal responsável pela efetivação do vínculo nessa relação (Brasil, 2001; Silva e Dalmaso, 2002; Tomaz, 2002; Rosa e col., 2004; Levy e col., 2004; Silva e col., 2005; Zanchetta e col., 2005; Bornstein e Stotz, 2008).

"Os agentes de saúde é o elo que liga a família com o médico, com o enfermeiro, sabe? [...] Nossa eu ganho presente sabe, nossa, eu ganho abraço no meio da rua, entendeu? [...] Às vezes tem gente, igual fim de ano assim, vem muito parente pra casa das pessoas, aí ah, essa daqui que cuida de mim e tal, assim que vem aqui e me dá as coisas, traz o médico na minha casa, aí os filhos reúne e dá a gente um presente, brigado por cê tá cuidando da minha mãe, cuidando da minha vó!” ACS 4.

"Porque o agente de saúde ele é uma pessoa né, que lida com todo mundo, ele sabe da vida de todo mundo, né, é uma pessoa que tem que sê muito sincera pra trabalhá, né?! A gente sabe, fica sabeno coisa que às vezes nem a família sabe e a gente fica sabeno da pessoa, por exemplo, quando a pessoa fica grávida na família às vezes ela num tem coragem de contá pros pais mas conta pra gente!” ACS 11.

o ACS possui uma identidade comunitária e a importância do seu papel social o diferencia dos demais trabalhadores da saúde, principalmente ao atuarem como mediadores entre as diversas esferas de organização da vida social (Nogueira e col., 200o). Para Nunes e colaboradores (2002), essa posição estratégica de mediador entre a comunidade e o serviço de saúde os inscreve de forma privilegiada na dinâmica de implantação e de consolidação do novo modelo de saúde, atribuindo-lhes um caráter híbrido e polifônico, como podemos observar nos depoimentos abaixo:

"Igual nós já fomo em escola, já demos banho em criança, já tiramos piolho em criança, já tiramos bicho de pé de criança! [...] Quando a gente vê que tem uma coisa que tá demais nós reunimos e vamo fazê!!" ACS 4 .

"Tem umas casas aí que a gente vai umas 4 ou 5 vezes por mês ou mais, porque acaba atendeno umas mais por causa de um problema mesmo, né? [...] Pra sabê se tá tomano o remédio direito.” ACS 5 . 
"Se nóis fô plantá uma horta comunitária, a população ajuda, a comunidade ajuda! [...] Quando tem as reunião de Emater pra entregá semente, essas coisa assim, aí eu aviso..." ACS 9.

"Aí quando precisa, por exemplo, de acompanhá alguma família que num tem ninguém por eles a gente acompanha! [...] Porque às vezes a família, pessoas que num tem estudo e num conhece, chega lá fica meio perdido, né?!” ACS 10.

Vale ressaltar a identificação de duas dimensões principais na atuação dos ACS: uma dimensão técnica, relacionada à atenção aos indivíduos e às famílias, à prevenção de agravos e ao monitoramento de grupos com problemas específicos; e a dimensão política, que transcende a inserção da saúde no contexto geral de vida das famílias, sendo direcionada à organização da comunidade com vistas à transformação das condições de vida (Silva e Dalmaso, 2002).

No estudo de Zanchetta e colaboradores (2005), a maior preocupação dos ACS foi revelar o compromisso do sistema de saúde com a comunidade, contudo, eles perceberam-se impossibilitados de promover a saúde diante da necessidade de medidas intersetoriais para a reversão da miséria e o alcance de melhor perspectiva de vida para a população.

Situações como essas fazem com que a abordagem do ACS, muitas vezes, seja baseada principalmente no controle de doenças crônicas e na prevenção de outros agravos, através do esclarecimento de dúvidas, da criação de vínculos de confiança, do reforço à solidariedade e escuta das demandas.

Muitas vezes os profissionais de saúde sentemse impotentes diante dos determinantes sociais da saúde, deparando-se com problemas como a miséria, o desemprego, a falta de higiene, a fome, entre tantas outras situações para as quais não há cura imediata, mas são tão graves que precisam ser cuidadas. Nesse sentido, ouvir o que a comunidade tem ou precisa dizer é acolher e, então, o acolhimento passa a ser uma forma de cuidar e pode ser o primeiro passo para ampliar o diálogo e gerar possibilidades e oportunidades (Duarte e col., 2007).

“Às vezes a pessoa nem precisa de cê tá lá pra leva remédio! Na verdade só d'ocê chega lá e conversá a pessoa já tranquiliza, né?!" ACS 2.
"Muitas vezes o paciente quer conversar com você, né? Que eles vão acostumano! Eles vão passano os pobrema, ah eu tô com uma dificuldade, aconteceu isso comigo ontem... Aí qué contá pra gente, aí eu fico lá, escuto!" ACS 3.

Para Silva e colaboradores (2005), uma das maneiras pelas quais o ACS contribui efetivamente para a materialização da integralidade no cuidado em saúde se dá quando ele busca dar respostas positivas às demandas da população. Além do mais, no momento em que se estabelece uma ação em saúde como prática de cuidado, cria-se uma parceria entre profissional e indivíduo buscando as origens, os significados do problema e as formas de enfrentá-lo (Silva e Dalmaso, 2002).

"Às vezes a gente já chega na casa encontra um problema e qué resolvê logo! Então eu já trago pro enfermeiro e a gente tenta solucioná." ACS 6.

No entanto, de acordo com Cotta e colaboradores (2007, p. 281), "para o enfrentamento das condições adversas faz-se necessária a identificação e definição não só das necessidades e demandas em saúde, mas também das condições institucionais para viabilização das ações e dos caminhos a serem percorridos - o que inclui a formação adequada dos profissionais de saúde para atuar no SUS e nos seus diferentes níveis - especialmente na atenção básica -, de modo a tornálos capazes de enfrentar os problemas resultantes da pobreza e da desigualdade social, tão presentes no cotidiano brasileiro".

\section{A Capacitação e Educação Permanente como Es- tratégia de Potencialização para a Reorientação do Modelo de Atenção em Saúde}

Para Tomaz (2002, p. 85,87), com a implantação do PSF o papel do ACS foi ampliado, exigindo novas competências nos campos político e social, principalmente ligadas à promoção da saúde. Entretanto, o processo de qualificação desse profissional ainda é desestruturado, fragmentado, e, na maioria das vezes, insuficiente para desenvolver as competências necessárias para o adequado desempenho de seu papel.

No município em estudo, nenhum ACS tinha experiência prévia de trabalho no PSF, sendo que apenas 54,6\% receberam algum tipo de orientação antes de iniciar o trabalho e $81,8 \%$ relataram ter participado de cursos de capacitação depois que já estavam trabalhando: 
"Porque a gente tem trenado, às vezes a gente acompanha quando tem esses cursos! Mas eu comecei a trabalhá sem curso nenhum, aí a gente vai aprendendo é no dia a dia, né?! É dia a dia...” ACS 10.

Quanto ao conhecimento e à apreensão dos ACS de Cajuri em relação ao SUS, seus princípios e diretrizes, apenas $27,3 \%$ dos entrevistados demonstraram ter algum tipo de apreensão, ainda que apresentando alguns conceitos inadequados:

"Tem que atendê a todos, né, com igualdade! [...] Não olha a quem, não pode negá atendimento a ninguém, qualquer que seja. $\varepsilon$ assim, olhar os casos mais urgentes, que é um direito de todos mas tem coisa que vai tê que separá, né?!" ACS 3.

"Equidade... Universalidade... Ah, eu sei equidade, integralidade! Equidade acho que é o que trata a igualdade, é isso? Eu confundo eles tudo!" ACS 4.

"Integridade... Ai num lembro de cabeça! [...] Tratáas pessoas iguais, não excluí ninguém... Todo mundo né, nós somos todos iguais, de cor, se tem dinheiro, se é pobre, se é rico, num importa!” ACS 6.

Todavia, em relação ao conhecimento e à apreensão dos princípios e diretrizes do PSF, 36,4\% dos ACS souberam definir PSF adequadamente e $81,8 \%$ relataram alguma de suas principais características/diretrizes.

Resultados semelhantes foram encontrados por Cotta e colaboradores (2006) em Teixeiras-MG e por Rosa e colaboradores (2004) na Bahia, demonstrando a inadequação do nível de apreensão e conhecimento dos princípios do sistema de saúde pelos profissionais. Ademais, de acordo com Rosa e colaboradores (2004), apesar de os ACS identificarem-se como trabalhadores do SUS, eles não conseguiam incorporar o PACS/PSF enquanto programas integrantes desse sistema, o que vai ao encontro dos resultados obtidos neste estudo.

Essa dificuldade para entender o novo sistema e o seu funcionamento pode estar relacionada à formação profissional, uma vez que um grande volume de trabalhos presentes na literatura evidencia que a formação do ACS continua centrada no controle tecnológico da doença, fazendo com que ele reproduza a visão fragmentada e reducionista do modelo biomédico em sua prática (Pedrosa e Teles, 2001; Nunes e col., 2002; Rosa e col., 2004; Silva e col., 2005; Cotta e col., 2006; Buchabqui e col., 2006; Duarte e col., 2007; Besen e col., 2007; Bornstein e Stotz, 2008).

Uma das consequências dessa formação baseada no modelo de educação tradicional dos cursos médicos é a atuação do ACS, não raras vezes, como "polícia sanitária”, conforme podemos observar no seguinte depoimento:

"Nas visitas tem os agentes que sabe mais sobre as famílias, sobre os poblema das famílias, sobre a medicação, se tem um curativo, gestante! [...] Hoje cêtem que olhá tudo, cartão, peso, altura, vacina se tá em dia, se foi no médico, se num foi cê tem que ficá cobrano, hoje em dia é bem, bem fiscalizado!" ACS 8.

Além disso, a abordagem puramente biológica não consegue preparar os profissionais para lidarem com toda a complexidade do processo saúde-doençaadoecimento no seu cotidiano de trabalho, gerando insegurança, impotência e, muitas vezes, percepções e atitudes incoerentes com o funcionamento do atual sistema de saúde.

"O SUS dificulta muito as pessoas pras consultas, pra internação, as pessoa tem que ficá enfrentando fila e mais fila. Eles tinham que priorizá! A pessoa chegô lá fez sua ficha e pronto! Entra pro médico. Tinha que chegá e sê atendido na hora, e não acontece! Por isso que morre tanto aí na, nas fila de hospital..." ACS 2.

"Eu acho que eu num sô capaz de trabalhá do jeito que precisa! [...] É uma responsabilidade que eu acho que eu num tô dano conta direito, do jeito que é!” ACS 11.

Nesse sentido, a capacitação e a educação permanente da equipe multiprofissional, em especial do ACS, são fundamentais para que os profissionais busquem atender às necessidades das famílias, direcionando o olhar e as ações de saúde para além das práticas curativas. É necessário, ainda, que os serviços de saúde e seus profissionais adotem uma forma de interação inovadora, contextualizada e em consonância com os valores das famílias nos cenários social e político (Noronha e col., 2009).

De acordo com Silva e Dalmaso (2002, p.181), o ACS se vê como organizador do acesso (cadastrador e orientador do uso dos serviços) e 'olheiro' da equipe na captação de necessidades, identificação de priori- 
dades e detecção de casos de risco para a intervenção. Diante disso, a capacitação do ACS deve contemplar conhecimentos diversos em torno da questão do processo saúde-doença, ultrapassando a perspectiva puramente biomédica e incorporando outros saberes que o habilitem nesse processo de interação cotidiana com as famílias (Nunes e col., 2002; Rosa e col., 2004; Buchabqui e col., 2006; Cotta e col. 2007).

Ademais, o processo de capacitação do ACS deve se basear na lógica do modelo da produção social da saúde e enfatizar os princípios do SUS, compreendidos e incorporados em sua prática, para que eles atuem com autonomia e segurança, promovendo o cuidado e o acolhimento, e possam contribuir seguramente com a consolidação desse novo sistema.

Também é preciso romper com a formação baseada na concepção "bancária”, para a qual a educação é o ato de depositar, transferir e transmitir valores e conhecimentos para seres de adaptação e ajustamento, passivos, ingênuos, acríticos e possuidores de um poder criador mínimo (Freire, 1987), o que constitui um obstáculo para o pleno desenvolvimento do potencial dos profissionais de saúde.

Para isso, os cursos de capacitação precisam estar fundamentados no desenvolvimento de competências, utilizando métodos de ensino-aprendizagem inovadores, reflexivos, críticos e centrados no educando, cujos objetivos centrais devem ser transformá-los em sujeitos pró-ativos (Tomaz, 2002; Mitre e col., 2008; Duarte e col., 2007).

Desse modo, o processo de formação ocupará potencialmente o papel de uma ação cultural para a libertação como um autêntico ato de conhecer, assumindo uma atitude comprometida de quem não apenas quer descrever o que se passa e como se passa, mas uma atitude de quem quer, sobretudo, transformar a realidade, para que o que agora se passa de tal forma, venha a passar-se de forma diferente no futuro (Freire, 2002).

\section{Entraves Presentes no Cotidiano do Trabalho do ACS: perfil profissional, valorização e sobrecarga}

Além da implementação de uma política de capacitação inovadora, é preciso que haja uma reflexão acerca do perfil profissional desejado para o ACS, uma vez que, para muitos, o significado de ser ACS representa a oportunidade de emprego (Silva e Dalmaso, 2002; Rosa e col., 2004). Essa realidade é verificada principalmente nos municípios de pequeno porte e se apresentou de maneira expressiva para a maioria dos ACS $(81,8 \%)$ de Cajuri:

"Não escolhi, fui escolhida, né? Eu era professora, não tinha mais sala de aula e eles me passaram, a prefeitura me passou pra sê agente comunitária de saúde." ACS 5 .

"Eu trabalhava assim como lavradora, né, eu ajudava o meu marido na roça, aí surgiu essa oportunidade aí eu comecei a trabalhar como agente de saúde.” ACS 10.

Quando questionadas sobre a intenção de continuar trabalhando no PSF, muitas consideravam o trabalho de ACS como algo temporário, até que surgisse outra oportunidade melhor de trabalho:

"Ah, enquanto eu tiver estudando, pra terminar meus estudos." ACS 1.

"Eu tô fazeno o curso, se saíalguma coisa pra mim! [...] Eu penso em deixá algum dia, mas só quando aparecê alguma coisa que fô melhor do que eu tô." ACS 10.

Os resultados desse estudo apontam como causas da desmotivação em relação à profissão de ACS tanto os baixos salários quanto a sobrecarga e desvalorização do trabalho.

"Eu tô estudando pra isso e gastando pra isso, porque no PSF a gente ganha um salário, que não vale de nada e a gente trabalha muito! Acho que é uma profissão que trabalha mais que qualquer outra, $o$ tanto que a gente anda e o tanto que a gente pensa e não vale a pena não!" ACS 5 .

"Quando alguma coisa dá errada dá vontade de desistí, então eu acho que eu num queria mais não. Eu tô um pouco desgastada!” ACS 6.

"Os usuário?! [...] Tem uns que num dá valor à gente, no que a gente faz. Ah, esse negócio do'ceis trabalhá no PSF, ceis fica mais é atoa, ceis fica na boa vida... Igual os profissionais que trabalha junto com a gente, às vez um dá valor a gente mais que o outro! [...] Nem sempre a gente acha que é valorizado do jeito que a gente queria, num é cantá parabéns masé pelo menos pá podêsabê que a gente tá trabalhano, sério!" ACS 11. 
Vários estudos demonstram que os ACS encontram dificuldades para cumprir com sua função (Silva e Dalmaso, 2002; Levy e col., 2004; Ferraz e Aerts, 2005; Duarte e col., 2007; Bornstein e Stotz, 2008). Para Nunes e colaboradores (2002, p.1641), a inclusão do ACS no PSF representa um aumento significativo de trabalho e de responsabilidade, sem que isso seja acompanhado de aumento salarial correspondente. Além disso, a posição do ACS no interior da equipe de saúde da família revela-se ainda mais crítica quando se compara o seu salário com o de outros membros da equipe, de forma que o sentimento de desvalorização do seu trabalho torna-se particularmente evidente se consideramos a hipótese de que o ACS é tido como personagem-chave do PSF.

Nesse sentido, ressalta-se a necessidade de se garantir uma capacitação adequada para o ACS, além de se criar estratégias de valorização e motivação para o exercício do trabalho desse profissional tão importante para o PSF.

\section{Considerações Finais}

É evidente que o ACS possui um papel essencial para a consolidação do SUS, não só por facilitar o acesso da população às ações e serviços de saúde, mas principalmente por ser o elo entre as equipes de saúde e a comunidade; fortalecendo as relações, facilitando o potencial diagnóstico das situações de risco e atuando como agente de organização da comunidade com vistas à transformação de suas condições de saúde.

No entanto, "não se pode colocar nas costas do ACS o árduo e complexo papel de ser a 'mola propulsora da consolidação do SUS'. Na prática, esse processo depende de um conjunto de fatores técnicos, políticos, sociais e o envolvimento de diferentes atores" (Tomaz, 2002, p.85--86). Para isso, é preciso incluir reflexões sobre o SUS, seus princípios e diretrizes no processo de capacitação dos profissionais de saúde, visando romper com a visão reducionista e fragmentada que ainda prevalece, tornando esses importantes atores coparticípes do processo de implementação do SUS no cotidiano dos municípios e comunidades.

Do mesmo modo, o processo de capacitação deve estar baseado na vivência da prática, permitindo a reflexão critica e o enfrentamento de situações reais, de forma que a reconstrução de significados ultrapasse uma aprendizagem baseada simplesmente na reprodução teórica do conhecimento e apele para uma aprendizagem que tenha como pressuposto a participação ativa do ACS e a integração da teoria com a prática.

Finalmente, parafraseando o sanitarista Gastão Wagner (Campos, 2007, p. 17), "tenho a impressão de que o SUS é melhor que o Brasil, mais generoso do que nós”. Assim, há que se ressaltar que maiores esforços valem à pena para melhorar a prática de trabalho dos profissionais de saúde, em especial do ACS, de forma a contribuir efetivamente para a consolidação do SUS.

\section{Referências}

BARDIN, L. Análise de Conteúdo. Lisboa: Edições 70; 2008.

BESEN, C. B. et al. A Estratégia Saúde da Família como objeto de educação em saúde. Saúde e Sociedade, São Paulo, v. 16, n. 1, p. 57-68, jan./abr. 2007.

BORNSTEIN, V. J.; STOTZ, E. M. Concepções que integram a formação e o processo de trabalho dos agentes comunitário de saúde: uma revisão de literatura. Ciência \& Saúde Coletiva, Rio de Janeiro, v. 13, n. 1, p. 259-68, jan./fev. 2008.

BRASIL. Ministério da Saúde. Portaria №. 1886/ GM, de 18 de dezembro de 1997. Aprova as Normas e Diretrizes do Programa de Agentes Comunitários de Saúde. Brasília, DF, 1997. Disponível em: <www. saude.gov.br>. Acesso em: 7 mar. 2008.

BRASIL. Ministério da Saúde. Decreto No 3.189, de 4 de Outubro de 1999. Fixa diretrizes para o exercício da atividade de Agente Comunitário de Saúde e dá outras providências. Brasília, DF, 1999. Disponível em: <www.saude.gov.br>. Acesso em: 8 fev. 2008.

BRASIL. Ministério da Saúde. Secretaria Executiva. Programa Saúde da Família. Brasília, DF, 2001.

BRASIL. Ministério da Saúde. Lei No ${ }^{\circ}$ 10.507, de 10 de julho de 2002. Cria a profissão de Agente Comunitário de Saúde e dá outras providências. Brasília, DF, 2002. Disponível em: <www.saude.gov. br>. Acesso em: 8 fev. 2008. 
BRASIL. Ministério da Saúde. Secretaria de Atenção à Saúde. Departamento de Atenção Básica. Política Nacional de Atenção Básica. Portaria n ${ }^{\circ}$ 648/GM de 28 de março de 2006. 4. ed. Brasília, DF, 2007. (Série E. Legislação de Saúde. Série Pactos pela Saúde 2006). p 9-55.

BRASIL. Ministério da Saúde. Departamento de Atenção Básica. Agentes Comunitários de Saúde, Equipes de Saúde da Família e Equipes de Saúde Bucal em atuação: competência novembro/20o8. Disponível em: <http://dtr2oo4.saude.gov.br/dab/ docs/abnumeros/resumo_por_uf_12_2008.pdf >. Acesso em: 12 mar. 2009.

BRASIL. Ministério da Saúde. Avaliação normativa do Programa Saúde da Família no Brasil: monitoramento da implantação e funcionamento das equipes de saúde da família: 2001-2002. Brasília, DF, 2004.

BRASIL. Ministério da Saúde / Fundação Oswaldo Cruz. Saúde da Família: avaliação da implementação em dez grandes centros urbanos: síntese dos principais resultados. Ministério da Saúde. 2. ed. Brasília, DF, 2005.

BUCHABQUI, J. A.; CAPP, E.; PETUCO, D. R. S. Convivendo com agentes de transformação: a interdisciplinaridade no processo de ensino/ aprendizado em saúde. Revista Brasileira de Educação Médica, Rio de Janeiro, v. 30, n. 1, p. 32-8, jan.-abr. 2006.

CAJURI (MG). Secretaria Municipal de Saúde. Informações sobre a gestão do sistema de atenção básica e composição das equipes de saúde da família 2008. Cajuri, 2008. [dados não publicados].

CAMPOS, G. W. O SUS é melhor que o Brasil. Radis, Rio de Janeiro, v. 62, p. 16-7, out. 2007.

COTTA, R. M. M.; MENDES, F. F., MUNIZ J. N. Descentralização das políticas públicas de saúde: do imaginário ao real. Viçosa: UFV - Cebes. 1998.

COTTA, R. M. M., et al. Pobreza, injustiça e desigualdade social: repensando a formação de profissionais de saúde. Revista Brasileira de Educação Médica, Rio de Janeiro, v. 31, n. 3, p. 278-86, set./dez. 2007.
COTTA, R. M. M., et al. Sobre o conhecimento e a consciência sanitária brasileira: o papel estratégico dos profissionais e usuários no sistema sanitário. Revista Médica Minas Gerais, Belo Horizonte, v. 16, n. 1, p. 2-8, 2006.

DUARTE, R. L.; SILVA JUNIOR, D. S.; CARDOSO, S. H. Construindo um programa de educação com agentes comunitários de saúde. Interface, Botucatu, v. 11, n. 23, p. 439-47, set.-dez. 2007.

FERRAZ, L.; AERTS, D. R. G. C. O cotidiano do agente comunitário de saúde no PSF em Porto Alegre.

Ciência \& Saúde Coletiva, Rio de Janeiro, v. 10, n. 2, p. 347-55, abr./jun. 2005.

FLEURY, S. Democracia, descentralização e desenvolvimento: Brasil e Espanha. Rio de Janeiro: Ed. FGV, 2006.

FRANCO, T.; MERHY, E. PSF: contradições e desafios. In: CONFERÊNCIA NACIONAL DE SAÚDE ON-LINE, 1999, Belo Horizonte/Campinas. Disponível em: <http://www.datasus.gov.br/cns/temas/tribuna/ PsfTito.htm>. Acesso em: 10 abr. 2008.

FREIRE, P. Pedagogia do oprimido. Rio de Janeiro: Paz e Terra, 1987.

FREIRE, P. Ação cultural para a liberdade e outros escritos. 10. ed. São Paulo: Paz e Terra, 2002.

IBGE - INSTITUTO BRASILEIRO DE GEOGRAFIA E ESTATÍSTICA. Síntese de Indicadores demográficos. Disponível em: <http://www.ibge.gov.br/cidadesat/ default.php>. Acesso em: 28 maio 2008.

LEVY, F. M.; MATOS, P. E. S.; TOMITA, N. E. Programa de agentes comunitários de saúde: a percepção de usuários e trabalhadores de saúde. Cadernos de Saúde Pública, Rio de Janeiro, v. 20, n. 1, p. 197-203, jan.-fev. 2004.

MENDES, E. V. Uma agenda para a saúde. São Paulo: Hucitec, 2006.

MINAYO, M. C. S. Avaliação por triangulação de métodos. Rio de Janeiro: Fiocruz, 2005.

MINAYO, M. C. S. O desafio do conhecimento: pesquisa qualitativa em saúde. 10. ed. São Paulo: Hucitec / Rio de Janeiro: Abrasco, 2007. 
MITRE, S. M., et al. Metodologias ativas de ensinoaprendizagem na formação dos profissionais de saúde: debates atuais. Ciência \& Saúde Coletiva, Rio de Janeiro, v. 13, supl. 2, p. 2122-44, dez. 2008.

NOGUEIRA, R. P.; SILVA, F. B.; RAMOS, Z. V. O. A vinculação institucional de um trabalhador sui generis: o agente comunitário de saúde. Rio de Janeiro: Ipea, 200o. (Textos para discussão, 735).

NORONHA, M. G. R. C. S.; et al. Resiliência: nova perspectiva na Promoção da Saúde da Família? Ciência \& Saúde Coletiva, Rio de Janeiro, v. 14, n. 2, p. 497-506, mar./abr. 2009.

NUNES, M. O., et al. O agente comunitário de saúde: construção da identidade desse personagem híbrido e polifônico. Cadernos de Saúde Pública, Rio de Janeiro, v. 18, n. 6, p. 1639-46, nov./dez. 2002.

PEDROSA, J. I.; TELES, J. B. M. Consenso e diferenças em equipes do Programa Saúde da Família. Revista de Saúde Pública, São Paulo, v. 35, n. 3, p. 303-11, jun. 2001.

ROSA, A. S.; CAVICCHIOLI, M. G. S.; BRÊTAS, A. C. P. O significado que o agente comunitário de saúde atribui ao seu trabalho no processo de construção do Sistema Único de Saúde no Brasil. Acta Paulista de Enfermagem, São Paulo, v. 17, n. 3, p.255-61, jul./set. 2004 .

SANTOS, J. L. F.; WESTPHAL, M. F. Práticas emergentes de um novo paradigma de saúde: o papel da universidade. Estudos Avançados, São Paulo, v. 13, n. 35, p. 71-88, jan./abr. 1999.
SCHERER, M. D. A.; MARINO, S. R. A.; RAMOS, F. R. S. Rupturas e resoluções no modelo de atenção à saúde: reflexões sobre a estratégia saúde da família com base nas categorias kuhnianas. Interface, Botucatu, v. 9, n. 16, p. 53-66, set./fev. 2005.

SILVA, J. A.; DALMASO, A. S. W. Agente comunitário de saúde: o ser, o saber, o fazer. Rio de Janeiro: Ed. Fiocruz, 2002.

SILVA, R. V. B., et al. Do elo ao laço: o agente comunitário na construção da integralidade em saúde. In: PINHEIRO, R.; MATTOS, R. A. Cuidado: as fronteiras da integralidade. Rio de Janeiro: Cepesp/ UERJ, Abrasco, 2005. p. 75-90.

SOUZA, E. R., et al. Construção dos instrumentos qualitativos e quantitativos. In: MINAYO, M. C. S.; ASSIS, S. G.; SOUZA, E. R. Avaliação por triangulação de métodos. Rio de Janeiro: Fiocruz, 2005. p. 133-56.

TOMAZ, J. B. C. O agente comunitário de saúde não deve ser um "super-herói”. Interface, Botucatu, v. 6, n. 10, p. 75-94, fev. 2002.

ZANCHETTA, M. S., et al. Educação, crescimento e fortalecimento do agente comunitário de saúde: estudo etnográfico. Online Brazilian Journal of Nursing, v. 4, n. 3, 2005. Disponível em: <http://www. uff.br/nepae/objnursing.htm>. Acesso em: 4 dez. 2007. 